\title{
REVIEW
}

\section{A Scoping Review of Well-being Assessment and Interventions in Student Pharmacists}

\author{
Katelynn Mayberry, PharmD, ${ }^{\mathrm{a}}$ Lorenzo Villa Zapata, PharmD, PhD, ${ }^{\mathrm{a}}$ Michael Byers, ${ }^{\mathrm{a}}$ Maria Miller Thurston, \\ PharmD ${ }^{\mathrm{a}, \mathrm{b}}$ \\ ${ }^{a}$ Mercer University, College of Pharmacy, Atlanta, Georgia \\ ${ }^{\mathrm{b}}$ Editorial Board Member, American Journal of Pharmaceutical Education, Arlington, Virginia
}

Corresponding Author: Maria Miller Thurston, Mercer University, College of Pharmacy, 3001 Mercer University Dr., DuVall 161, Atlanta, GA 30341. Tel: 678-547-6253. Email: Thurston_mm@mercer.edu

Submitted June 29, 2021; accepted August 31, 2021; ePublished September 2021

Objective. To review the literature assessing student pharmacist well-being and the impact of well-being associated interventions.

Findings. Of the 15 studies included, six assessed student pharmacist well-being while nine evaluated the impact of a well-being intervention. There are various approaches to assessing student pharmacist well-being. The body of literature suggests poor student pharmacist well-being overall. Since well-being is multifaceted and individualized, some pharmacy schools identified various ways to incorporate tailored well-being activities, including mindfulness, into required, elective, and co-curricular experiences within the Doctor of Pharmacy program, with varying outcomes.

Summary. This review highlights the limited and variable information available on the assessment of student pharmacist well-being as well as unique strategies to incorporate well-being initiatives into the doctor of pharmacy curriculum. Schools of pharmacy should identify student pharmacist well-being needs through a standardized well-being assessment instrument and provide meaningful well-being resources and interventions within the curriculum. There is a growing need for faculty to invest in student pharmacist mental wellness in addition to academic success. Future accreditation Standards will inform the Academy on how to advance well-being initiatives.

Keywords: Student pharmacist, well-being, wellness, mindfulness, curriculum

\section{INTRODUCTION}

Well-being is a state of health encompassing the physical, emotional, and mental conditions of an individual. In 1954, the World Health Organization (WHO) originally defined health as "not merely the absence of disease or infirmity, but a state of complete physical, mental, and social well-being." being in which every individual realizes his/her/their own potential, can cope with the normal stresses of life, can work productively and fruitfully, and is able to make a contribution to his/her/their community." 2 The WHO acknowledges that there is no universally accepted definition of well-being due to differing cultural perspectives and concepts. These concepts range from socioeconomic status and quality of personal relationships, to simply being happy. ${ }^{3}$ When a person's well-being becomes compromised over a long period of time, mental health issues may arise. These conditions contribute to job burnout, decreased work productivity, as well as feelings of exhaustion and depletion.

Mental health and well-being are of special importance to Colleges and Schools of Pharmacy. Within Standards 14 and 15 of the Accreditation Council for Pharmacy Education (ACPE) Standards 2016, there is mention of health and wellness in regard to promoting wellness and healthy behaviors in the management of various disease states focused on patient care. The ACPE Standards also call for pharmacy programs to have appropriate resources to promote student success and well-being. ${ }^{4}$

In 2019, the American Association of Colleges of Pharmacy (AACP) collaborated with the American Pharmacists Association, Accreditation Council for Pharmacy Education, the National Association of Boards of Pharmacy, and the National Alliance of State Pharmacy Associations to provide recommendations for student pharmacist well-being. This consensus report underscored the importance of applying strategies that address self-care techniques for well-being and preventing burnout, rewards and incentives for engaging in well-being activities, and formal training to address behavioral health. These types of interventions are more valuable than ever due to the stress pharmacists and student pharmacists have experienced while serving communities during the COVID-19 pandemic. ${ }^{5}$

It is imperative to assess and understand the well-being of student pharmacists in order to best craft methods of outreach, support, and intervention. Such methods may help to prevent negative coping strategies in practice and provide 
optimal levels of patient care and support. However, well-being is extremely difficult to quantify because well-being has a dynamic, evolving definition tied to many subjective factors. Multiple survey instruments have been developed in an attempt to appropriately assess well-being. ${ }^{6-9}$

The objective of this scoping review is two-fold, (1) to examine current assessments and measurements of student pharmacist well-being and (2) to evaluate interventions utilized to improve student pharmacist well-being, in order to determine the gaps and limitations in available literature.

\section{METHODS}

Following the Arksey and O'Malley framework, ${ }^{10-11}$ this scoping review was undertaken to identify studies that assessed student pharmacists' well-being and any well-being-associated interventions employed in the pharmacy curriculum. This review was conducted in compliance with the Preferred Reporting Items for Systematic Reviews and Meta Analyses extension for Scoping Reviews (PRISMA-ScR).

Three electronic databases (PubMed, ERIC, and EMBASE) were searched using a combination of keywords and Medical Subject Headings (MeSH). Due to the limited amount of literature available, initial search terms of "student pharmacist well-being" yielded insufficient evidence. The authors broadened the search to all health care professionals and higher education students to retrieve a sufficient number of articles for screening. In order to capture all the possible well-being literature on this novel topic, the authors did not set a time limit on the articles retrieved. Keywords included: "students, public health/psychology", "students, medical/psychology", "students, pharmacy/psychology", "burnout, psychological", "health", "health promotion", "wellness", "wellbeing”, "well-being”, and "well being”. MeSH terms included "student/pharmacy", "health", and "health promotion". To further identify articles assessing student pharmacist well-being or targeted well-being interventions, the investigators also conducted a manual review of references of the included articles to identify relevant articles not found in the initial search for potential inclusion.

One hundred twenty-seven results were imported into the reference management software Zotero, (Vienna, Virginia). Screening was undertaken by four reviewers. Each member reviewed all imported articles, and the reference list of each included article was scanned to identify other potential articles. Studies were included if they pertained to assessments of well-being in student pharmacists or reported on curricular activities in pharmacy education that focused on well-being. Studies that involved interprofessional education were included if pharmacy was one of the disciplines evaluated. Study limits were set on English language. All study designs were eligible. Studies were excluded if they did not focus on student pharmacists' well-being. The assessment of well-being strategies described in each paper were tagged with appropriate keywords and were also categorized with subheadings of the well-being domains defined by the Centers for Disease Control and Prevention (CDC) (physical, economic, social, emotional, psychological, life satisfaction, and engaging activities). ${ }^{12}$ The process of tagging studies to well-being categories was accomplished through prospective discussion among the reviewers about the studies' parameters. For example, studies that assessed students' perceptions of stress using the Perceived Stress Rating Scale were tagged to both the survey/questionnaire and stress/stress management categories, while an article describing how a well-being mindfulness activity was incorporated into the curriculum was tagged to the mindfulness/curriculum/intervention category.

\section{RESULTS}

The screening in the abstract phase excluded 36 results, leading to 91 results screened in full text for potential eligibility (Figure 1). Each of the included studies and were reviewed in detail by the research team. After detailed fulltext review of the 91 articles, $15(n=2062)$ were included in the results based on the set criteria and tagged accordingly (Table 1).

Of the 15 articles included in this review, seven of the studies $(n=507)$ were conducted in the United States, and eight ( $\mathrm{n}=1555)$ were conducted internationally. Six of the studies sought to assess student pharmacist well-being using various rating scales $(n=1589)$. Four other studies incorporated a well-being intervention into the pharmacy curriculum $(n=193)$, while the effects of mindfulness implementation were assessed in the remaining five studies $(n=280)$. The initiative of student pharmacist well-being is a fairly new concept with all included studies except one being published after 2019.

Six studies were found that have assessed the well-being of student pharmacists (Table 2). Each study identified chose a different approach in assessing student pharmacist well-being. One study evaluated the quality of life (QOL) of 711 student pharmacists as a predictor of well-being by using a validated WHO-BREF instrument. ${ }^{13}$ The investigators found that $82.1 \%$ of the students had a fair overall QOL and poor well-being in all four domains. The RAND-36 is another widely used scale that measures QOL. One pharmacy school assessed 104 (53\%) first- and third-year student pharmacists using the RAND-36, which assesses the domains of emotional well-being, physical pain, and emotional 
functioning, and found a decline in well-being in third-year student pharmacists. ${ }^{14}$ Other schools of pharmacy have assessed psychological well-being in 447 (98.9\%) student pharmacists as a composite of three survey instruments: Mood Rating Scale (MRS), Self Esteem Scale (SES), and Satisfaction with Life (SWL) scale. By using a composite result of these domains, the investigators drew conclusions regarding student pharmacists' psychological well-being and its positive relationship with burnout. ${ }^{15}$ Furthermore, a qualitative assessment of 49 (36.8\%) first-year student pharmacists' well-being was conducted through thematic analysis of student pharmacists' reflections on personal well-being. Investigators conducted the analysis by coding the student pharmacists' reflections of their own well-being and developing unique factors of well-being based on their specific student population. Factors of well-being discovered through the thematic analysis included workload, learning environment culture and values, meaningful pharmacy school experiences, relationships, and personal factors. ${ }^{16}$ While the aforementioned studies assessed student pharmacist wellbeing at a single point in time, only one study was found that assessed student pharmacist well-being longitudinally. One investigator conducted a longitudinal assessment of $76(100 \%)$ first-year student pharmacists with a survey instrument that defined well-being by the Gallup well-being domains and assessed the students for 29 weeks. ${ }^{17}$ The Gallup defined well-being domains include: career wellbeing, community wellbeing, financial wellbeing, physical wellbeing, and social wellbeing. ${ }^{18}$ By assessing student pharmacists' well-being over time, the investigators discovered that different domains of well-being can fluctuate throughout the course of a year.

Literature is now available that raises awareness regarding the existence of poor well-being in student pharmacists; to address this, colleges and schools of pharmacy have implemented different strategies to incorporate wellbeing activities into pharmacy curricula (Table 3). Some studies included semester-long interventions, while others incorporated a one-day activity. Certain schools included the well-being activities within a co-curricular experience, while others embedded the well-being initiatives within a required or elective course. There were nine studies that were included in this analysis that developed a targeted intervention to improve student pharmacist well-being. In Finland, one school of pharmacy incorporated a seven-week optional course that was structured in an Acceptance and Commitment Therapy (ACT) format. The ACT course format included introduction to the psychoeducational method, audio and visual experiential exercises, and participant reflections. The investigators found that $40(86 \%)$ students' well-being and time management increased during the course. ${ }^{19}$ Another example of a longitudinal well-being activity was performed by the University of Kentucky, where four, month-long well-being activities were introduced in a required pharmacy course in which participation was optional for extra credit. These well-being activities were a single, month-long challenge that students incorporated into their daily routine and wrote reflections on at the end of each month to try and "nudge" longterm behavioral changes to improve well-being. The 126 (93\%) students that completed the challenges reported the attempt to continue the healthy habits as they were identified as useful. ${ }^{20}$ An alternate strategy is to incorporate a single well-being activity into a required course. The University of Waterloo incorporated a single "Check In" activity in a required course that consisted of a background reading, an in-person lecture component, and a faculty-student mentoring session. ${ }^{21}$ The investigators found that the $76(63 \%)$ student pharmacists reported the "Check-in" activity as rewarding, and both students and faculty reported it as a positive experience. Finally, 49 (36\%) first-year student pharmacists at one school of pharmacy wrote reflections on personal well-being in one of the required courses in the curriculum. These reflections were then used to find common themes, (availability and accessibility of institutional resources, personal time management and organizational strategies, personal mental health and physical health strategies, and activities that maintain social relationships) and a discussion and lecture on well-being then followed. ${ }^{22}$ All of the aforementioned strategies have their own unique benefits and limitations.

Of the nine studies that included a targeted intervention in the curriculum to improve student pharmacist wellbeing, five studies specifically focused on mindfulness and meditation. One technique that has been used to help nurture well-being is the practice of mindfulness and meditation. The strategy of mindfulness meditation has been used for decades to help reduce stress and promote overall well-being. ${ }^{23}$ Some pharmacy schools have incorporated mindfulness activities to promote well-being in student pharmacists. One intervention incorporated the use of the mindfulness meditation app, HeadSpace, to help improve student pharmacist well-being. Ninety-two (70\%) student pharmacists voluntarily practiced ten minutes of mindfulness meditation in the app every day for four weeks as an extracurricular activity. Results demonstrated enhanced mental well-being as well as decreased perceived stress. ${ }^{24}$ Another university incorporated a voluntary, extracurricular, six-month yoga and meditation class to help improve student well-being through anxiety and stress reduction. ${ }^{25}$ Seventeen students, including nine (53\%) students from the school of pharmacy, experienced an improvement in their mindfulness and a decrease in their perceived stress score. Finally, a school of pharmacy in Ireland incorporated a voluntary, four-week mindfulness course into the pharmacy curriculum. ${ }^{26}$ Fifty-one student pharmacists realized a significant decrease in stress and increase in mindfulness when compared to the 48 controls. This mindfulness course originated from ideas generated through thematic analysis of focus group member 
contributions, in which student pharmacists vocalized interest in incorporating mindfulness as a coping skill for stress reduction. ${ }^{27}$ The thematic analysis of feedback from 20 student pharmacists revealed five key elements: "so much to do with so little time, the role of lecturers, wanting to do well, learning by doing, and using mindfulness as a coping tool." This mindfulness course consisted of a two-hour class session with group discussions followed by a 20-minute at home exercises each week. After incorporating the in-person mindfulness course, the pharmacy school also developed a fourweek online delivery version of the same course with similar results. Fifty-two (37\%) student pharmacists experienced a significant increase in professional efficacy and observation skills and a decrease in stress levels. ${ }^{28}$

\section{DISCUSSION}

The concept of assessing and promoting wellness in other health care professionals, such as nursing and medical students, is not new. There have also been numerous publications assessing and highlighting mental health challenges experienced by student pharmacists including stress, anxiety, depression, and burnout; however, literature focused specifically on well-being is limited. ${ }^{29-30}$ Although the authors have found publications on how to assess the well-being of student pharmacists, each publication used a different assessment tool. This may be due to the multifactorial nature of well-being and the fact that there is no universally accepted definition.

Since the promotion of well-being is multi-faceted, the approach can be varied and individualized to meet the unique needs of the individuals involved. Our results yielded diverse interventional approaches to help promote wellbeing in schools of pharmacy. Additionally, since well-being is subjective to the individual, it raises the question of how to best incorporate well-being initiatives that meet the needs of a diverse student body. One approach is to incorporate unique well-being activities into the required curriculum or co-curriculum. Most schools of pharmacy already require a seminar class or professional development course as part of their curriculum, which may serve as a useful location for such programming. Other approaches include making targeted well-being experiences an elective or optional activity in which students can voluntarily participate. Out of the targeted interventions reviewed, all yielded positive feedback from the students who participated.

Initiatives involving student well-being seem to have gained traction in 2017-18 with the charge to the AACP Student Affairs Standing Committee to develop a resource guide for its members on how to implement well-being strategies for student pharmacists. The report recommended discussions and programming on the topic of well-being, the creation of a well-being task force, and the curricular integration of well-being ${ }^{31}$ In 2018-19, the AACP Academic Affairs Standing Committee was charged with assessing and promoting student pharmacist well-being. ${ }^{32}$ The 2018 -19 Academic Affairs Report recommended that AACP should consider developing programs that can evaluate student pharmacist wellbeing and identify factors affecting well-being. ${ }^{32}$ The standing committee's reports have led to the development of policies for schools of pharmacy that may influence future well-being initiatives. ${ }^{33}$ In 2018 , AACP hosted a Fall Institute on strategies to promote a culture of well-being among students and faculty. The committee's charge for 2022 is to develop a resource guide for member institutions to help with implementing holistic well-being strategies for all students, faculty, and staff. ${ }^{34}$ The newly created AACP Well-being and Resiliency Community is also developing a Well-being Toolkit for its member institutions. ${ }^{35}$

The American Pharmacist Association (APhA) published its recommendations from its National Consensus Conference, including that schools should offer ongoing education and training on student pharmacist well-being and that ACPE Standards require annual well-being assessments for student pharmacists to guide organizational initiatives. ${ }^{5}$ In response to this, the draft of Standards 2025 address student pharmacist well-being in Standards 14 and 15. These draft Standards emphasize the importance of developing organizational resources and services to support well-being as well as specific policies to promote a well-being friendly environment. ${ }^{36}$ Once finalized, these future accreditation standards will likely include more defined key elements associated with student pharmacist well-being. In the meantime, schools of pharmacy can utilize the aforementioned AACP Policies on Professional Education as guidance. ${ }^{33}$

The promotion of well-being is needed now more than ever, especially for student pharmacists. With the inclusion of well-being recommendations in the draft of Standards 2025, it is crucial now for all major organizations/associations to collaborate on well-being initiatives for standardization. After reviewing the literature, it would be helpful for colleges of pharmacy to share a standard definition of student pharmacist well-being that is incorporated into its governing documents. Future researchers could develop a standardized and validated instrument to assess well-being, specifically geared toward student pharmacists. If a standard definition and assessment can be determined, this would lead to possible secondary meta-analysis to measure impactful interventions and their associated outcomes. One limitation to standardization is how the interpretation of individual well-being is contingent on subjective experiences and diverse backgrounds. 
Experts have also proposed possible approaches to nurturing well-being in student pharmacists. One expert stated, "Well-being initiatives in a college of pharmacy should focus on decreasing student perceived stress and increasing perceptions of satisfaction and fulfillment." ${ }^{\text {"S7 }}$ Student pharmacist well-being initiatives can come from interested individuals, dedicated faculty, and student organizations from the schools of pharmacy. One thematic analysis of first-year student pharmacists yielded four individual approaches on how to cope with stress and well-being. The four main areas that individual students identified to help promote well-being were: personal health, time management, socialization, and the use of institutional resources. ${ }^{22}$ The investigators found that student pharmacists who were more involved in cocurricular activities studied more, had higher GPAs, and had stronger relationships with faculty, staff, and peers. ${ }^{16}$ Religion and spirituality of student pharmacists also positively affected their emotional and mental well-being, which are also important for student success. ${ }^{38}$ Another recommendation was for the establishment of faculty and staff cohorts that assist and support students with low resilience and well-being. Student organizations can also develop events to promote resilience and well-being supplemental to the curricular teachings. These events could include healthy meal offerings, organized exercise activities, outside speakers, social events, and community service. ${ }^{39}$ Identifying and recruiting students, faculty, and staff members to lead these initiatives provides diverse perspectives on well-being and decreases the burden on individual students. ${ }^{40}$

It is imperative for schools of pharmacy to identify opportunities for targeted interventions tailored specifically to the needs of its own students, rather than adopting a universal intervention. It is unlikely that a universally accepted wellbeing intervention will be practically relevant for all students. Common themes that arose from this review are a need to address the availability of organizational resources, personal self-help strategies, and the incorporation of mindfulness within the curriculum. These themes could help guide schools of pharmacy when crafting institution-specific well-being interventions. One example of meeting this organizational resource need is for schools to incorporate a certified Mental Health First Aid (MHFA) training course for its students. This MHFA training program has been shown to help mitigate the stigma of mental health struggles and nurture a well-being culture within a school of pharmacy. ${ }^{41} \mathrm{APhA}$ has also partnered with the Mayo Clinic for students to use the My Well-being Index Assessment app which allows individuals to track their well-being and plots progress over time. Not only does it keep a record of one's progress, but it also shows how one's well-being compares to the average well-being scores across all pharmacists. Additionally, the app provides tailored resources to meet identified well-being needs. ${ }^{42}$ This app is an example of how to support students with self-help strategies.

\section{Well-being and COVID-19}

The COVID19 pandemic has taken a toll on student pharmacists' purpose well-being, social well-being, financial well-being, physical well-being, and community well-being at our schools of pharmacy, as outlined by Gallup. ${ }^{43}$ With new virtual and remote learning environments, students may have increased anxiety about completing their coursework efficiently. The ever-changing landscape of pharmacy education amid COVID-19 led to a delay in research opportunities as well as missed professional meetings and ceremonies. There has also been anxiety regarding how students would conduct their experiential rotations and take licensing examinations. Schools of pharmacy may need to assist students with potential well-being challenges arising from the COVID-19 pandemic. Such assistance can include helping students focus on what they can control like maintaining a regular schedule and promoting emotional well-being by doing something they enjoy each day. ${ }^{44}$

\section{CONCLUSION}

The promotion of student pharmacist well-being is a multifaceted initiative. There are several ways to assess wellbeing and provide impactful interventions based on perceived needs and the culture of the student body. Student pharmacists are the future of the pharmacy profession and schools of pharmacy must nurture students' well-being not only in terms of academic performance, but also emotional health. Incorporation of a "well-being curriculum" is critical for student success following the COVID-19 pandemic. Pharmacy faculty are well positioned to talk to students and advise them that well-being challenges may arise during their time spent in pharmacy school. During these conversations, caring, openness, and understanding are of upmost importance.

\section{REFERENCES}

1. Misselbrook D. W is for wellbeing and the WHO definition of health. Br J Gen Pract. 2014;64(628):582. doi:10.3399/bjgp14X682381 
2. World Health Organisation. Promoting Mental Health: Concepts, Emerging Evidence, Practice- Summary Report. World Health Organization Geneva. 2004. https://www.who.int/mental_health/evidence/en/promoting_mhh.pdf. Accessed March 17, 2021.

3. Multilateral agencies launch a joint plan to boost global health goals. WHO International. https://www.who.int/news/item/24-09-2019-multilateral-agencies-launch-a-joint-plan-to-boost-global-healthgoals. Accessed March 31, 2021.

4. Accreditation Council for Pharmacy Education. Accreditation Standards and Key Elements for the Professional Program in Pharmacy Leading to the Doctor of Pharmacy Degree ("Standards 2016"). Published February 2015. https://www.acpe-accredit.org/pdf/Standards2016FINAL.pdf. Accessed 15 May 2021.

5. Enhancing Well-Being and Resilience Among the Pharmacist Workforce: A National Consensus Conference. Pharmacist.com. https://aphanet.pharmacist.com/enhancing-well-being-and-resilience-among-pharmacistworkforce-national-consensus-conference. Accessed March 7, 2021.

6. Mirza W, Mirza AM, Saleem MS, et al. Well-being Assessment of Medical Professionals in Progressive Levels of Training: Derived from the WHO-5 Well-being Index. Cureus. 2018;10(12):e3790. doi:10.7759/cureus.3790

7. Garcia-Williams AG, Moffitt L, Kaslow NJ. Mental health and suicidal behavior among graduate students. Acad Psychiatry. 2014;38(5):554-560. doi:10.1007/s40596-014-0041-y

8. Huo T, Guo Y, Shenkman E, Muller K. Assessing the reliability of the short form 12 (SF-12) health survey in adults with mental health conditions: a report from the wellness incentive and navigation (WIN) study. Health Qual Life Outcomes. 2018;16(1):34. doi:10.1186/s12955-018-0858-2

9. Sabourin AA, Prater JC, Mason NA. Assessment of mental health in doctor of pharmacy students. Curr Pharm Teach Learn. 2019;11(3):243-250. doi:10.1016/j.cptl.2018.12.004

10. Arksey H, O’Malley L. Scoping studies: towards a methodological framework. Int J Soc Res Meth. 2005;8(1):1932. doi: 10.1080/1364557032000119616

11. Levac D, Colquhoun H, O’Brien D. Scoping studies: advancing the methodology. Implement Sci. 2010;5:Article 69.

12. CDC. Well-Being Concepts. Centers for Disease Control and Prevention. Published 2019. https://www.cdc.gov/hrqol/wellbeing.h. Accessed March 5, 2021.

13. Okoro RN, Muslim JO, Biambo AA. Quality of life of pharmacy students in Northern Nigeria. International Journal of Pharmacy Practice. 2020;28(4):395-404. doi:10.1111/ijpp.12624

14. Edgell ET, Caplette MD, Gregor KJ, Flynn MT, Coons SJ. Well-Being and Functional Status of Pharmacy Students: A Preliminary Assessment. Journal of Pharmacy Technology. 1997;13(2):84-88. doi: $10.1177 / 875512259701300210$

15. Cho E, Jeon S. The role of empathy and psychological need satisfaction in pharmacy students' burnout and wellbeing. BMC Med Educ. 2019;19(1):43. doi:10.1186/s12909-019-1477-2

16. Abraham O, Babal JC, Brasel KV, Gay S, Hoernke M. Strategies first year doctor of pharmacy students use to promote well-being. Currents in Pharmacy Teaching and Learning. Published online August 28, 2020. doi:10.1016/j.cpt1.2020.08.005

17. Hagemeier NE, Carlson TS, Roberts CL, Thomas M. A Longitudinal Analysis of First Professional Year Pharmacy Student Well-being. AJPE. 2020;84(7):ajpe7735. doi:10.5688/ajpe7735

18. Rath T. The Five Essential Elements of Well-Being. Gallup.com. Published May 4, 2010. https://www.gallup.com/workplace/237020/five-essential-elements.aspx. Accessed May 27, 2021.

19. Asikainen H, Kaipainen K, Katajavuori N. Understanding and promoting students' well-being and performance in university studies. Journal of University Teaching \& Learning Practice. 2019;16(5). Available at:https://ro.uow.edu.au/jutlp/vol16/iss5/2

20. Cain J. Effectiveness of Issuing Well-being Challenges to Nudge Pharmacy Students to Adopt Well-being Protective Behaviors. AJPE. 2020;84(8):ajpe7875. doi:10.5688/ajpe7875

21. Fernandes HVJ, Richard C, Bynkoski K, Ewan B, Houle SKD. Check-In: An Educational Activity to Address Well-Being and Burnout among Pharmacy Students. Pharmacy. 2020;8(4):184. doi:10.3390/pharmacy8040184

22. Babal JC, Abraham O, Webber S, Watterson T, Moua P, Chen J. Student Pharmacist Perspectives of Factors that Influence Wellbeing during Pharmacy School. AJPE. Published online February 11, 2020. doi:10.5688/ajpe7831

23. Jon Kabat-Zinn. MBSR Overview. Mindfulness Based Stress Reduction. https://mbsrtraining.com/mbsrsyllabus/mbsr-overview/. Accessed May 1, 2021. 
24. Zollars I, Poirier TI, Pailden J. Effects of mindfulness meditation on mindfulness, mental well-being, and perceived stress. Currents in Pharmacy Teaching and Learning. Published online August 2019. doi:10.1016/j.cptl.2019.06.005

25. Lemay V, Hoolahan J, Buchanan A. Impact of a Yoga and Meditation Intervention on Students' Stress and Anxiety Levels. AJPE:6.

26. O’Driscoll M, Sahm LJ, Byrne H, Lambert S, Byrne S. Impact of a mindfulness-based intervention on undergraduate pharmacy students' stress and distress: Quantitative results of a mixed-methods study. Currents in Pharmacy Teaching and Learning. 2019;11(9):876-887. doi:10.1016/j.cptl.2019.05.014

27. O’Driscoll M, Byrne S, Kelly M, Lambert S, Sahm LJ. A Thematic Analysis of Pharmacy Students' Experiences of the Undergraduate Pharmacy Degree in Ireland and the Role of Mindfulness. AJPE. 2019;83(1). doi:10.5688/ajpe6457

28. O’Driscoll M, Byrne S, Byrne H, Lambert S, Sahm LJ. An online mindfulness-based intervention for undergraduate pharmacy students: Results of a mixed-methods feasibility study. Currents in pharmacy teaching \& learning. 2019;11(9):858-875. doi:10.1016/j.cptl.2019.05.013

29. Garber MC, Huston SA, Breese CR. Sources of stress in a pharmacy student population. Currents in Pharmacy Teaching and Learning. 2019;11(4):329-337. doi:10.1016/j.cptl.2019.01.014

30. Hirsch JD, Nemlekar P, Phuong P, et al. Patterns of Stress, Coping and Health-Related Quality of Life in Doctor of Pharmacy Students. AJPE. 2020;84(3):7547. doi:10.5688/ajpe7547

31. Miller ML, Boyer C, Emerson MR, et al. Report of the 2017-2018 Student Affairs Standing Committee. Am J Pharm Educ. 2018;82(7):7159. doi:10.5688/ajpe7159

32. Gregory DF, Boje KM, Carter RA, et al. Leading Change in Academic Pharmacy: Report of the 2018-2019 AACP Academic Affairs Committee. Am J Pharm Educ. 2019;83(10):7661. doi:10.5688/ajpe7661

33. American Association of Colleges of Pharmacy House of Delegates. AACP Policies on Professional Education.; 2020. Accessed March 31, 2021. https://www.aacp.org/sites/default/files/2021-

04/hod_commulative_policy_1980_2020.pdf

34. American Association of Colleges of Pharmacy Committees. AACP Standing Committees.; 2022. Accessed August 24, 2021. https://www.aacp.org/article/aacp-committees

35. American Association of Colleges of Pharmacy. AACP Connect. Wellbeing and Resiliency Community; 2021. Accessed August 24, 2021. Well-Being and Resiliency Community - American Association of Colleges of Pharmacy (aacp.org)

36. Acreditation Counsel for Pharmacy Education. ACPE Standards 2025 Revision Feedback; 2021. Accessed August 24, 2021. Standards Revision - Formstack

37. Haas J, Pamulapati LG, Koenig RA, Keel V, Ogbonna KC, Caldas LM. A call to action: Pharmacy students as leaders in encouraging physical activity as a coping strategy to combat student stress. Currents in Pharmacy Teaching and Learning. 2020;12(5):489-492. doi:10.1016/j.cptl.2020.01.001

38. Purnell MC, Johnson MS, Jones R, et al. Spirituality and Religiosity of Pharmacy Students. AJPE. 2019;83(1). doi:10.5688/ajpe6795

39. Kang K, Lopez CFO, Fear BS, Granko RP. Tactics to improve resilience and well-being among pharmacy students. American Journal of Health-System Pharmacy. 2019;76(18):1374-1376. doi:10.1093/ajhp/zxz143

40. Schlesselman LS, Cain J, DiVall M. Improving and Restoring the Well-being and Resilience of Pharmacy Students during a Pandemic. AJPE. 2020;84(6):ajpe8144. doi:10.5688/ajpe8144

41. McCormack Z, Gilbert JL, Ott C, Plake KS. Mental health first aid training among pharmacy and other university students and its impact on stigma toward mental illness. Curr Pharm Teach Learn. 2018;10(10):1342-1347. doi:10.1016/j.cptl.2018.07.001

42. My Well-being Index. Pharmacist Well-being Index. Mayo Clinic. Accessed on August 24, 2021. Pharmacist Well-Being Index $\mid$ Well-Being Index $\mid$ Go Beyond Burnout (mywellbeingindex.org)

43. Stone, J. K., \& Pate, A. N. (2020). The Impact of COVID-19 Through the Eyes of a Fourth-Year Pharmacy Student. American Journal of Pharmaceutical Education, 84(6). https://doi.org/10.5688/ajpe8146

44. Brazeau GA, Frenzel JE, Prescott WA Jr. Facilitating Wellbeing in a Turbulent Time. AJPE. 2020;84(6):ajpe8154. doi:10.5688/ajpe8154 
Figure 1. Flow Chart of Study Selection According to PRISMA-ScR Guidelines

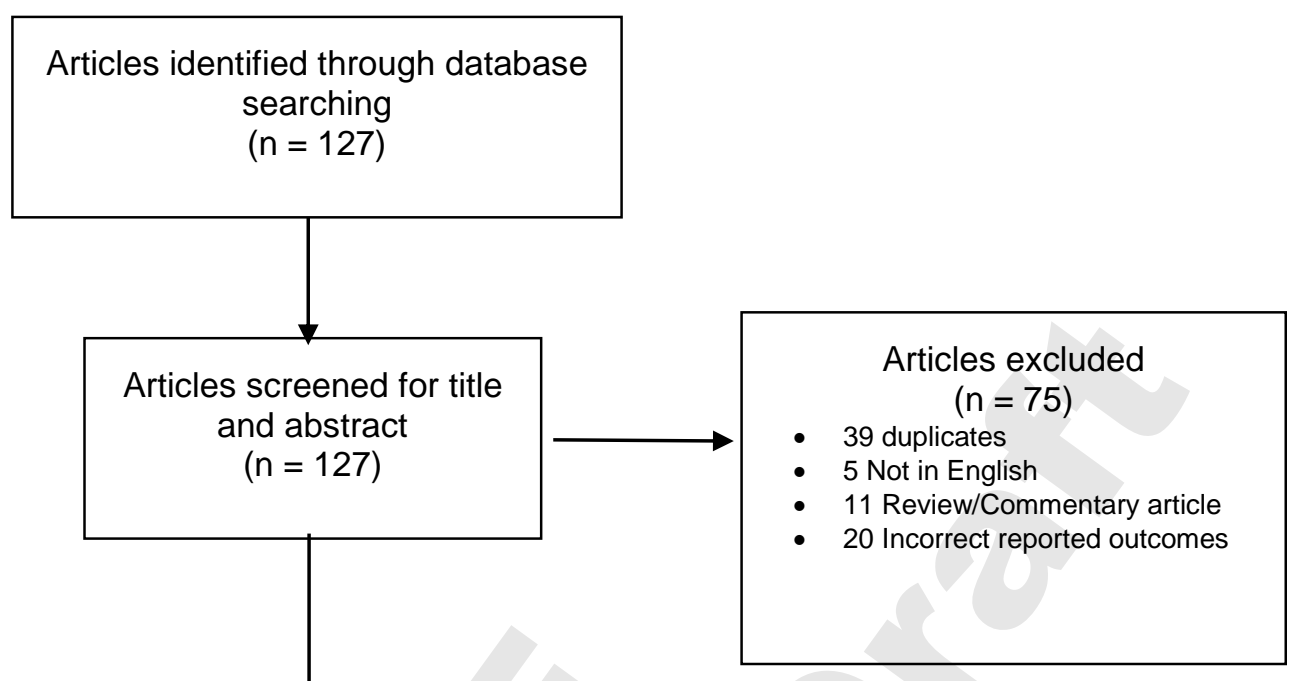

Full-text articles excluded, with reasons $(n=37)$

- 16 Pharmacy not included

- 12 Not focus on student pharmacist wellbeing

- 9 Review/Commentary articles

Final Studies Included $(n=15)$ 


\begin{tabular}{cc}
\hline Citation and Tags & Objective
\end{tabular}

\section{Well-being Assessment}

Okoro, 2019

QOL of pharmacy students in Northern Nigeria

Tags:

Pharmacy Student

Well-being

Survey and Questionnaire Self-assessment

Quality of Life

Edgell, 1995

Well-Being and Functional Status of Pharmacy Students:

A Preliminary Assessment

Tags:

Pharmacy student

Well-being

Survey and Questionnaire

Self-reported

Cho and Jeon, 2019

The role of empathy and psychological need satisfaction in pharmacy students' burnout and well-being

Tags:

Pharmacy student

Burnout

Empathy

Well-being

Survey and Questionnaire

Self-Assessment

Babal and Abraham, 2020

Student Pharmacist Perspectives of Factors that Influence

Wellbeing during Pharmacy School

Tags:

Pharmacy Student

Well-being

Stress

Curriculum

Student reflection

Thematic Analysis

Hagemeier, 2020

A Longitudinal Analysis of First Professional Year

Pharmacy Student Well-being

Tags:

Pharmacy student

Well-being
To assess the QOL of Nigerian pharmacy

students

To investigate QOL predictors

To investigate how pharmacy education

affects the health status of student pharmacists

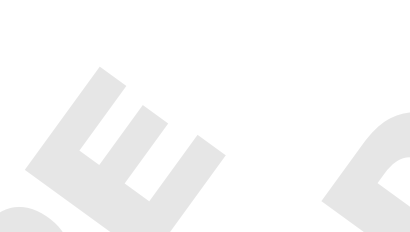

To examine the relationship between student pharmacists' empathy and psychological need satisfaction, levels of burnout, and

psychological well-being

Student pharmacists from three schools in Nigeria $(n=711)$

First- or third-year student pharmacists at the University of Arizona College of Pharmacy $(n=196)$

Student pharmacists from five South Korean universities

$(n=452)$

To explore first-year student pharmacis perspectives on the influence of individual, educational system, and healthcare system factors on their well-being

To assess and characterize student pharmacist well-being across the first professional year

To determine the relationship between the

number of exams taken, GPA, and well-being scores
First-year student Wisconsin during required course who consented to participate during the study period February-June 2019 $(n=49)$

\section{First-year student} pharmacists at East

Tennessee State University $(n=76)$ pharmacists at University of 
Survey and questionnaire

Self-assessment

Cantril self-anchoring scale

Gallup well-being domains

Opoku-Acheampong, 2017

Perceived stress and QOL of pharmacy students in

To assess the relationship between stress and QOL of student pharmacists

University of Ghana

Tags:

Pharmacy student

Well-being

Survey and Questionnaire

Self-reported

Quality of Life

\section{Required Curricular Well-being Interventions}

Asikainen, 2019

Understanding and promoting students' well-being and performance in university studies

Tags:

Pharmacy student

Well-being

Stress

Curriculum

Student Reflection

Survey and questionnaire

Cain, 2020

Effectiveness of Issuing Well-being Challenges to Nudge Pharmacy Students to Adopt Well-being Protective

Behaviors

Tags:

Pharmacy student

Well-being

Curriculum

Survey and questionnaire

Fernandes, 2020

Check-In: An Educational Activity to Address Well-

Being and Burnout among Pharmacy Students

Tags:

Pharmacy Student

Well-being

Curriculum

Student reflection

Abraham, 2020

Strategies first year doctor of pharmacy students use to promote well-being
To examine student pharmacists' experiences of a small ACT-based intervention that was implemented as a 7 -week course with weekly online modules

\section{To assess the effectiveness of well-being}

challenges in a pharmacy management course To influence student adoption of positive well-being behaviors

To develop an active-learning activity, called "Check-In," to teach and reflect on healthcare provider burnout

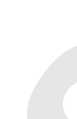

To assess strategies that first-year student pharmacists utilize to manage stress and promote well-being throughout the program
Student pharmacists at

University of Ghana ( $\mathrm{n}=110)$

Student pharmacists from

University of Helsinki

Finland $(\mathrm{n}=40)$

Third-year student

pharmacists at University of Kentucky (n=136)

Student pharmacists from

University of Waterloo

School of Pharmacy $(n=120)$

First-year student pharmacists from University of Wisconsin $(n=49)$ 
Curriculum

Student reflection

Thematic analysis

\section{Mindfulness Co-curricular Well-being Interventions}

\section{Zollars, 2019}

Effects of mindfulness meditation on mindfulness, mental well-being, and perceived stress

Tags:

\section{Pharmacy student}

Well-being

Mindfulness

Survey and questionnaire

Self-assessment

Headspace

Perceived stress

Lemay, 2019

Impact of a Yoga and Meditation Intervention on

Students' Stress and Anxiety Levels

Tags:

Pharmacy student

Well-being

Stress management

Mindfulness

Survey and questionnaire

Self-assessment

Yoga

Mindfulness Elective Curricular Well-being Interventions

O’Driscoll, 2019

A Thematic Analysis of Pharmacy Students' Experiences

of the Undergraduate Pharmacy Degree in Ireland and the

Role of Mindfulness

Tags:

Pharmacy student

Well-being

Focus Groups

Stress management

Thematic analysis

Mindfulness

O’Driscoll 2019
To investigate the effects of mindfulness meditation using the Headspace ${ }^{\mathrm{TM}}$ app on mindfulness, mental well-being, and perceived stress in student pharmacists

To evaluate the impact of a six-week yoga and meditation intervention on college students' stress perception, anxiety levels, and mindfulness skills

Students from University of Rhode Island, including student pharmacists $(n=20)$
First- through third-year student pharmacists at Southern Illinois School of Pharmacy $(n=92)$
To determine student pharmacists'

experiences of stress as a part of the current pharmacy degree

To explore the potential of incorporating the principles of mindfulness into the curriculum
Student pharmacists in all years from five schools in Ireland (undergraduate degree) $(n=20)$
To assess the quantitative effects of a mindfulness-based intervention on student
Student pharmacists from one school of pharmacy in Ireland $(n=99)$ 
Impact of a mindfulness-based intervention on

undergraduate pharmacy students' stress and distress:

Quantitative results of a mixed-methods study

Tags:

Pharmacy student

Well-being

Mindfulness

Curriculum

Survey and questionnaire

Self-assessment

O’Driscoll, 2019

An online mindfulness-based intervention for undergraduate pharmacy students: Results of a mixed-

methods feasibility study

Tags:

Pharmacy student

Well-being

Survey Questionnaire

Mindfulness

Curriculum

Stress management

Self-assessment

Abbreviations: ACT $=$ Acceptance and Commient Therapy; GPA= Grade Point Average; $\mathrm{QOL}=$ Quality of life pharmacist stress, distress, burnout, and mindfulness levels
To assess the feasibility and acceptability of an online mindfulness-based intervention To determine its effect on student pharmacist well-being
Student pharmacists from

four schools in Ireland

(undergraduate degree)

Table 2. Results of Literature Assessing Student Pharmacist Well-being

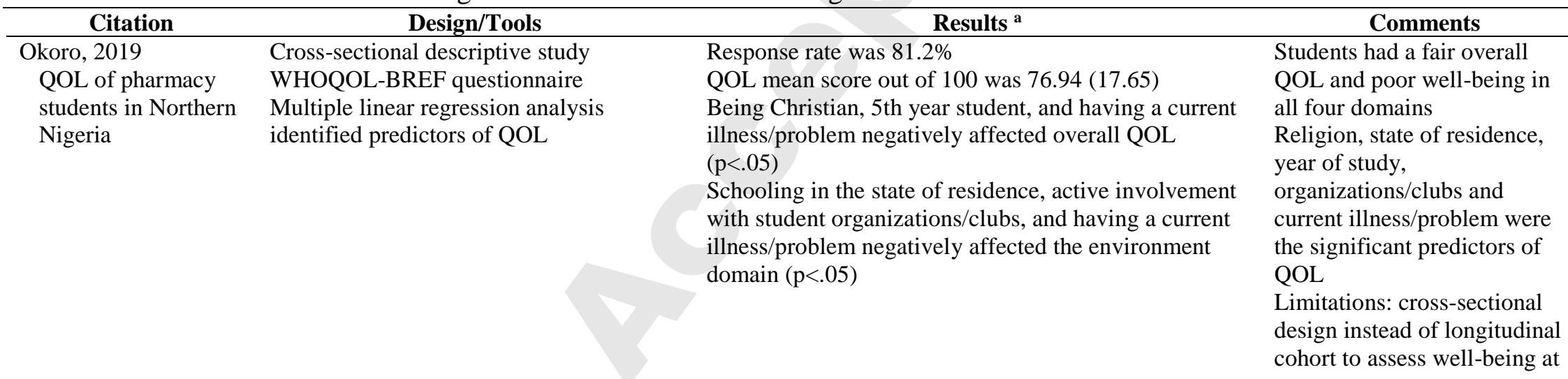


Edgell, 1995

Well-Being and

Functional Status of

Pharmacy Students:

A Preliminary

Assessment

Cho and Jeon, 2019

The role of empathy and psychological need satisfaction in pharmacy students' burnout and wellbeing

Babal and Abraham, 2020

Student Pharmacist Perspectives of

Factors that

Influence Wellbeing during Pharmacy

School

\section{Hagemeier, 2020}

A Longitudinal

Analysis of First

Professional Year

Pharmacy Student

Well-being
Well-being was assessed using the RAND Response rate was 84\%

36-Item Health Survey

Students were surveyed with several scales and results used structural equation modeling

The Jefferson Scale of Empathy (Health

Professions Students version) assessed empathy

The Activity-Feeling States Scale assessed psychological need satisfaction The Maslach Burnout Inventory Student Survey assessed burnout

Mood Rating Scale, Self-Esteem Scale, and Satisfaction with Life Scale assessed psychological well-being

Student pharmacists were required to submit reflective essays detailing the factors that most significantly contributed to their well-being

Qualitative thematic analysis was

performed using open and axial coding, hierarchical categorization, and representative theme determination

Students answered 6 questions (Likert scale 1-7) during each two-hour weekly class session (29 weeks)

Questions based on Gallup-defined wellbeing domains: (a) career well-being, (b) community well-being, (c) financial wellbeing, (d) physical well-being, and (e) social well-being semester $(\Delta 7.3, \mathrm{p}=.04)$ well-being $(\beta=0.18)$ $0.59)$ analysis 4.5 vs $4.8, \mathrm{p}=.018$ ) an individual level may have resulted in recall bias related to historical information Pharmacy school may affect students' functioning and wellbeing in different and unique ways between the classes, and the mean scores for the firstyear class remained stable during the semester $(\mathrm{p}=.53)$ The third-year class's mean scores for the emotional well-being and emotional problem-related role functioning scales decreased significantly during the

Response rate was $98.9 \%(n=447)$

Empathy was positively associated with psychological

Perceived satisfaction of psychological needs was positively related to psychological well-being $(\beta=$

Perceived satisfaction or psychological needs was strongly and negatively related to burnout $(\beta=-0.71)$

$36.8 \%(n=49)$ students submitted reflective essays for

Five themes identified for pharmacy student wellbeing: (a) workload; (b) learning environment culture and values; (c) meaningful pharmacy school experiences; (d) relationships; and (e) personal factors Student pharmacists did not consistently identify healthcare system factors as influencing well-being

$100 \%(n=76)$ students completed the study

All domains decreased by the end of fall semester (career mean $=5.5$ vs $4.8, \mathrm{p}>.001$; community mean= 5.4 vs $4.5, \mathrm{p}<.001$; financial mean $=4.7$ vs $3.9, \mathrm{p}=.001$ physical mean $=5.0$ vs $4.1, \mathrm{p}<.001$; social mean $=5.5$ vs $5.0, p=.016$; overall mean $=5.3$ vs $4.8, p=.003$ ).

Social well-being increased after winter break (mean=
Limitations: small sample size and students did not have to participate in both surveys

This study assessed well-being from a mood rating scale, selfesteem scale, and satisfaction with life scale

Education systems should consider students' empathy and psychological needs for student success and well-being Limitations: results used mean scores instead of individual items and were correlations thus not allowing for determination of a causal relationship

This study assessed well-being through thematic analysis Student pharmacists identified both education system and individual factors that influenced well-being Limitations: small sample size of only first-year students at a single institution

This study assessed well-being with a Likert scale from

Gallup-defined well-being domains

Demonstrated well-being fluctuates throughout the semester 
Score of 1-2 equaled suffering, 3-4 equaled struggling and 5-7 equaled striving

Opoku-Acheampong, 2017

Perceived stress and

QOL of pharmacy

students in

University of Ghana
The 10-item PSS and the WHOQOL scale were administered to the same participants at two time points: Time 1 (4 weeks into the semester) and Time 2 ( 8 weeks afterwards)
Physical well-being was the largest predictor of overall well-being in the fall

Social/career well-being was the largest predictor for overall well-being in the spring

Overall well-being was positively affected by number of exams $(\mathrm{r}=.56, \mathrm{p}<.05)$

$71.4 \%(n=110)$ students completed the study

The mean stress scores were higher at Time 2 compared to Time 1

No significant difference in stress for different year group $(\mathrm{p}=.44)$

Female students had higher stress scores compared to male students (19.6 vs. 17.4)

The main stressors identified were: large volume of material to be studied, laboratory report writing,

constant pressure to maintain good grades, and lack of leisure time
Limitations: small sample size of only first-year students at a single institution

The study reported

relationships between stress and various domains of QOL Limitations: only one school of pharmacy was surveyed and study did not account for nonresponse bias

a p-values are reported if available in the study

Abbreviations: PSS = Perceived Stress Scale; QOL= Quality of life; WHOQOL-BREF= World Health Organization Quality of Life Instrument

Table 3. Results of Literature Evaluating the Impact of Well-being Interventions Involving Student Pharmacists

\begin{tabular}{|c|c|c|c|}
\hline Citation & Design/Tools & Results $^{\text {a }}$ & Comments \\
\hline $\begin{array}{l}\text { Asikainen, } 2019 \\
\text { Understanding and } \\
\text { promoting students' } \\
\text { well-being and } \\
\text { performance in } \\
\text { university studies }\end{array}$ & $\begin{array}{l}\text { Students' well-being, experiences of stress, } \\
\text { organized studying, and psychological } \\
\text { flexibility were measured with questionnaires } \\
\text { at the beginning and end of a course } \\
\text { Students' experiences of how the course } \\
\text { affected studying were analyzed from open- } \\
\text { ended responses and reflective journal }\end{array}$ & $\begin{array}{l}45.7 \%(\mathrm{n}=21) \text { consented to analysis } \\
\text { Students' well-being and time management } \\
\text { increased during the course }(\Delta 4.66, \mathrm{p}=.001) \\
\text { Students experienced that the course affected } \\
\text { their studying }\end{array}$ & $\begin{array}{l}\text { This study demonstrated that } \\
\text { online course interventions can } \\
\text { foster students' well-being and } \\
\text { study skills } \\
\text { More research is needed to } \\
\text { identify the long-lasting effects } \\
\text { Limitations: small sample size } \\
\text { and potential reporting bias }\end{array}$ \\
\hline $\begin{array}{l}\text { Cain, } 2020 \\
\text { Effectiveness of } \\
\text { Issuing Well-being } \\
\text { Challenges to Nudge } \\
\text { Pharmacy Students to } \\
\text { Adopt Well-being } \\
\text { Protective Behaviors }\end{array}$ & $\begin{array}{l}\text { Well-being activities were implemented into } \\
\text { a required course with an extra credit point } \\
\text { for each completion }(0.2 \%) \\
\text { Focused on four challenges: cellphone use, } \\
\text { feelings of gratitude, sleep, and exercise } \\
\text { Post-activity survey captured completion, } \\
\text { intention to continue, and purpose for doing } \\
\text { said activity }\end{array}$ & $\begin{array}{l}93 \%(\mathrm{n}=126) \text { student pharmacists completed at } \\
\text { least one activity and } 21 \%(\mathrm{n}=28) \text { all four } \\
\text { activities } \\
\text { Main reason for completion was for extra credit } \\
\text { followed by promoting well-being } \\
46 \%-66 \% \text { of participants stated intent to continue } \\
\text { the well-being habits }\end{array}$ & $\begin{array}{l}\text { This promotes a strategy to } \\
\text { include optional well-being } \\
\text { assignments in a required } \\
\text { course } \\
\text { "Low cost" assignments led to } \\
\text { a shift in positive well-being } \\
\text { behaviors } \\
\text { Limitations: the success of } \\
\text { long-term adoption was based } \\
\text { on self-reported data }\end{array}$ \\
\hline
\end{tabular}


Fernandes, 2020

Check-In: An

Educational Activity

to Address Well-

Being and Burnout among Pharmacy

Students

Abraham, 2020

Strategies first year doctor of pharmacy students use to

promote well-being

Zollars, 2019

Effects of

mindfulness

meditation on

mindfulness, mental

well-being, and

perceived stress

\section{Lemay, 2019}

Impact of a Yoga and

Meditation

Intervention on

Students' Stress and

Anxiety Levels
Check-In course was comprised of a 20minute online lecture on healthcare provider burnout, two pre-readings on burnout among physicians, and an optional one-on-one session between individual students and faculty or staff member

Students rated their current mental health on a 10-point scale from reflection guide and reflected on questions focusing on energy expenditure, self-care, and self-compassion within the past, present, and future

Students were enrolled in the second semester of their first year of a four-year PharmD program

Students were required to write a two-page reflection before a small group discussion and lecture on their overall well-being while in a social and administrative sciences course Open and axial coding was conducted on the reflections using qualitative thematic analysis

Medication using the Headspace ${ }^{\mathrm{TM}}$ app for at least 10 minutes per day for four weeks Students at baseline completed the HPLP Data was collected from the pre/post surveys using the FFMQ, WEMWBS, and Cohen PSS

Six-week pilot program of a 60 -minute vinyasa flow yoga class once weekly, followed by guided meditation by trained faculty members

Students completed pre- and post-

intervention questionnaires to evaluate changes in: stress levels, anxiety levels, and mindfulness skills

The questionnaires consisted of: the BAI, the PSS, and the FFMQ
$63 \%(\mathrm{n}=76)$ student pharmacists participated in the activity

Check-In was reported as rewarding and overall positive for students and faculty

The personal connection with members from the school and the placement of the activity within the curriculum contributed to the success of the activity

$36.8 \%(n=49)$ student pharmacists reported multiple strategies to help cope with stressors and improve their well-being

Four themes emerged, including: (1) availability and accessibility of institutional resources, (2) personal time management and organizational strategies, (3) personal mental and physical health strategies, and (4) activities that maintain social relationships

$70 \%(\mathrm{n}=92)$ student pharmacists completed the study

Data revealed the intervention was associated

with enhanced mindfulness and mental well-

being and decreased perceived stress $(p<.001)$

Further analysis indicated that controlling for

various health promoting lifestyle behaviors

preserves the positive impact of mindfulness meditation as demonstrated

$85 \%$ participants completed the study $(n=17)$

Nine of the students were enrolled in the Doctor

of Pharmacy program and eight were enrolled in

other academic programs

Students' anxiety and stress scores decreased

significantly while their total mindfulness

increased significantly (BAI scores

Median $=-9, \mathrm{p}<.001 ;$ PSS scores

Median $=-8, \mathrm{p}<.001 ;$ FFMQ scores, Median=4.0,

$\mathrm{p}<.001)$

Changes in categorical data from pre- to post-

intervention on the BAI and PSS were significant,
Limitations: short duration of individual sessions and feedback was self-reported

P1 students are actively thinking about and participating in well-being activities Colleges and schools of pharmacy need to understand well-being strategies students use and identify approaches for supporting student needs Limitations: single school of pharmacy included and low participation rate

Mindfulness meditation improved the participants overall mental health

The data support that pharmacy schools adopt these practices in their curriculum

Limitations: students volunteered instead of being selected and potential incentive bias

Results suggest adopting a mindfulness practice may reduce stress and anxiety in student pharmacists

Limitations: small sample size, short duration, and selfreported outcomes 
O’Driscoll, 2019

A Thematic Analysis

of Pharmacy

Students'

Experiences of the

Undergraduate

Pharmacy Degree in

Ireland and the Role

of Mindfulness

\section{O’Driscoll 2019}

Impact of a

mindfulness-based

intervention on

undergraduate

pharmacy students'

stress and distress:

Quantitative results of

a mixed-methods

study

O’Driscoll, 2019

An online

mindfulness-based

intervention for

undergraduate

pharmacy students:

Results of a mixed-

methods feasibility
Focus groups and transcripts were coded using Braun and Clarke method to find themes

A 4-week MBSR course consisting of a two hours lecture plus 20 minutes of practice built into the curriculum

Stress was measured by PSS, Mental distress by GHQ, Empathy by JSPE, Burnout by MBI-SS, and Mindfulness by FFMQ

Adapted online mindfulness-based 4-week course with one-hour online classes and 20 minutes of daily practice

Optional non-graded course

Stress was measured by PSS, Mental distress

by GHQ, Empathy by JSPE, and mindfulness

by FFMQ with no students scoring in the "high" category for stress or anxiety on the post-intervention questionnaire

20 student pharmacists (no response rate provided) from all classes at three of the five schools were represented

Themes found: "so much to do; so little time," "role and availability of lecturer," "fear of failure," "learning by doing," and "mindfulness and coping tool"

Students were not aware of the support currently provided by the schools and welcomed the idea of a mindfulness course and stress prevention

$39.9 \%$ ( $n=99)$ student pharmacist responses were analyzed

Results showed student pharmacist improvement in all scales, but only the GHQ was statistically significant $(F=15.3, p<.005)$

Course evaluations were all positive that students felt they experienced benefit

$37 \%(\mathrm{n}=52)$ student pharmacists completed the course

Results showed improvement in PSS, GHQ,

JSPE, FFMQ, but not statistically significant

Qualitative analysis revealed that students found

the most benefit in stress reduction
This study precipitated the incorporation of a mindfulness course in the curriculum

Limitations: not all pharmacy schools in Ireland were represented in the study population

Small sample size and not meeting power could have led to less-than-optimal results Limitations: potential selfselection bias

Follow up intervention study from focus group

Limitations: $62 \%$ dropout rate and small sample size which did not meet power lead to insignificant results

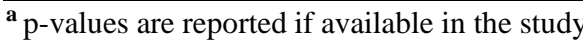

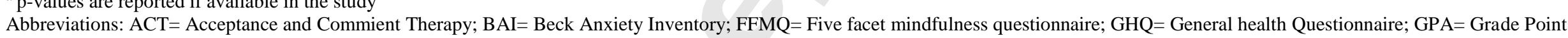

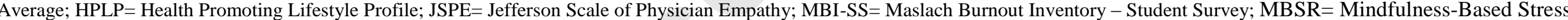

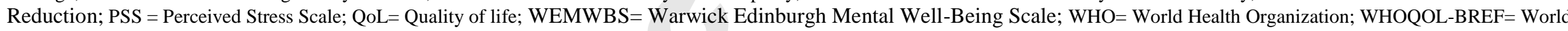
Health Organization Quality of Life Instrument 